\title{
Measuring social influence and group formation during evacuation process
}

\author{
Adriana Balboa, Arturo Cuesta, Daniel Alvear \\ University of Cantabria \\ Los Castros, Santander, Spain \\ balboaa@unican.es; cuestaar@unican.es; alveard@unican.es
}

\begin{abstract}
Evacuees are likely to respond and move forming groups. However specific data about grouping is generally unavailable and the relationship between response and movement times and specific groupings are unknown. Using a simple method, we measure behavioural cohesion of occupants during evacuation processes. The case study involves using the method in a bus station, a sport centre and a library. Results suggest that proximity (visual/verbal contact) is an important factor but not decisive in the formation of evacuation groups. Social ties and whether occupants share a target and/or an activity before the alarm are also deemed to be important factors. This study provides an exciting opportunity to advance our knowledge of social influence and group formation during evacuation.
\end{abstract}

Keywords: Collective behaviour; Evacuation groups; Behavioural cohesion; Social influence; Evacuation process

\section{Introduction}

Primary questions concerning collective behaviour during the evacuation process include how individuals reach a consensus and form groups and how this impacts life safety. It is known that individuals are influenced by others. This can also happen in response to ambiguous threat cues [1]. Collective behaviour can occur whenever people are confused or do not know what to do. Individuals work together to redefine the situation and propose a new set of actions, which is the product of the milling and keynoting process [2]. Several studies have shown that people behaviour in emergencies tends to be cooperative $[3,4]$. The common identity in response to the same threat would explain this. Evidence and theories support the idea that individuals form a group before evacuating and then continue their evacuation together until they reach safety [5].

Despite collective behaviour being important, most current evacuation models simulate agents as if they were not influenced by others. One agent can start the evacuation while others remain in the same room/place. In other words, no social influence is represented. There are methods for modelling the collective behaviour. However, to the authors' knowledge, this is not supported by empirical data. A quantitative method to measure collective behaviour in evacuees proposed in [6] is here applied to three evacuation scenarios to test its validity.

\section{Method}

\subsection{Formulation}

Collective evacuation behaviour denotes a reduction in the behavioural variability of individuals. Let $\mathrm{X}$ be a continuous behavioural random variable. Hence, the smaller the statistical dispersion of the variable $\mathrm{X}$ intragroup, compared to the statistical dispersion of the same variable $\mathrm{X}$ in all groups, the greater the collective behaviour. This can be expressed by the following statistical hypothesis:

$$
\begin{aligned}
& H_{0}: U C V_{i}<L C V_{t} \\
& H_{1}: U C V_{i} \nless L C V_{t}
\end{aligned}
$$


Where $U C V i$ is the upper confidence interval for the coefficient of variation $(\mathrm{CV})$ of $\mathrm{X}$ variable for the $i$-th potential evacuation group defined as a number of people who are located, gathered of classed together before the evacuation and $L C V t$ is the lower confidence interval for the coefficient of variation $(\mathrm{CV})$ of $\mathrm{X}$ variable for all the potential groups. There are various methods for estimating the confidence interval for a population CV [7, 8]. We propose to use the Median Modified Miller Estimator (Med Miller) $[9,10]$ and the Median Modified Curto and Pinto's with iid assumption (Med C\&P) [11] since skewed distributions are likely to be obtained and the variability can be measured in terms of the median rather than the mean. If the null hypothesis fails to reject, then we have preliminary evidence of collective behaviour among the members of the potential group. Then, we can go a step beyond and measure the behavioural cohesion of group members by:

$$
\gamma_{B_{i}}=1-\frac{C V_{i}}{C V_{t}}
$$

Where $C V_{i}$ is the coefficient of variation of the $\mathrm{X}$ variable in the $i$-th group and $C V_{t}$ is the coefficient of variation of the same $\mathrm{X}$ variable of all groups in the evacuation scenario. The higher the $\gamma_{B_{i}}$ coefficient the higher the cohesion (i.e. a value of 1 represents a perfect synchronization of group members). It is also possible to introduce a new variable $\left(\tilde{\gamma}_{B}\right)$ to characterize the degree of behavioural cohesion for a given evacuation scenario:

$$
\tilde{\gamma}_{B}=\frac{1}{n} \sum_{i=1}^{m} n_{i} \cdot \gamma_{B_{i}}
$$

Where $n$ is the number of occupants in the evacuation scenario, $m$ the number of evacuation groups in the evacuation scenario and $n_{i}$ the number of members for the $i$ - $t$ th group.

\subsection{Cases of study}

The case study involves three evacuation scenarios: 1) a bus station, 2) a sports centre and 3) a library. These scenarios represent different geometries, population distribution and activities performed by people before the evacuation.

The first scenario consisted of an evacuation experiment in an underground bus station in Madrid, Spain. In total 18 trials were conducted to analyse the people response to a terrorist attack. However, only one of these trials is analysed in this paper. In total 74 participants took part in the trial (average age 40.4 range 19-67). Between 6 and 9 participants were randomly assigned to the 10 boarding gates (see Fig. 1). The second scenario involved an unannounced evacuation drill in a sports centre at the University of Cantabria, Spain involving 78 naive students. Fig. 2 shows the distribution of occupants within the building before the alarm. The third scenario comprises an unannounced evacuation drill in a library of the Faculty of Economics and Business at the University of Cantabria, Spain with 33 naive students. Fig. 3 shows the initial distribution of the students in the library before the alarm.

The potential groups for the analysis were predefined by authors according to their initial location within the building i.e. occupants were likely to interact with each other and/or whether they share a target and/or an activity before the alarm. Video-cameras were used for the data collection. The following variables were considered to measure the group behaviour of the bus station and the sports centre: the response time $\left(t_{\text {res }}\right)$ defined as the time from the sounding of the alarm to deliberate evacuation movement (s) and the exit time ( $\left.t_{\text {exit }}\right)$ defined as time from the sounding of the alarm to leaving the building by an exit (s). For the library, only the response phase of evacuation was measured (i.e. we did not have enough time to cover the exits with the video-cameras). The variables measured were: the recognition time $\left(t_{\text {rec }}\right)$ defined as the time from the sounding of the alarm to the first response action such as collect belongings, shutdown laptop, etc. (s) and the response time $\left(t_{r e s}\right)$ the same as above. The defined variables were measured manually using an image processing software frame by frame. Datasets were transcribed into a spreadsheet for further analysis. 


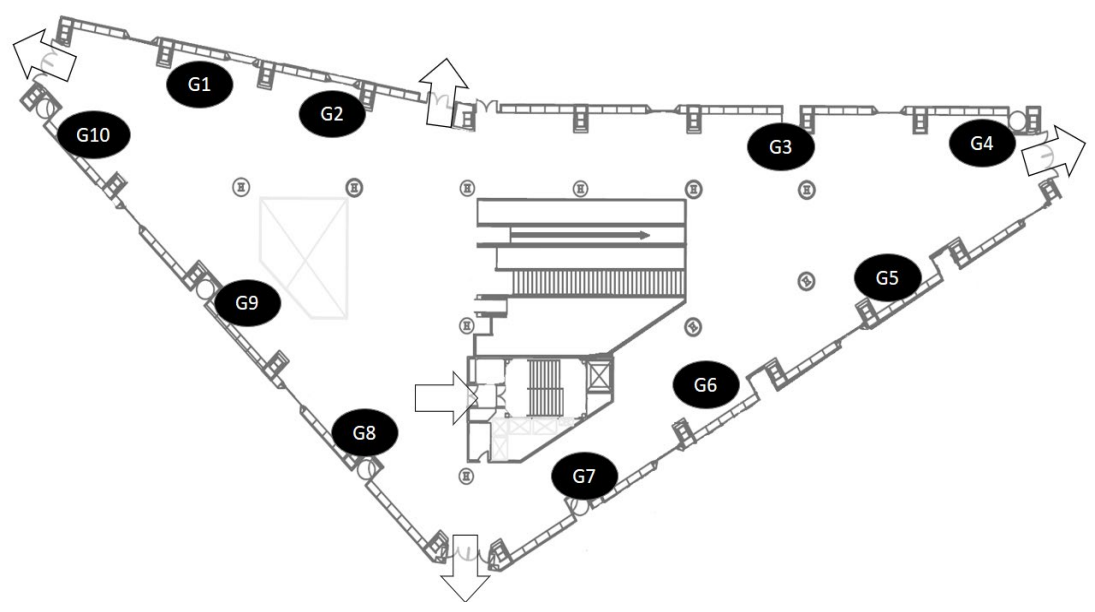

Fig. 1: Initial distribution of participants in the bus concourse before the alarm $(\mathrm{G} 1=6 ; \mathrm{G} 2=7 ; \mathrm{G} 3=6$; $\mathrm{G} 4=8$; $\mathrm{G} 5=7$; $\mathrm{G} 6=6 ; \mathrm{G} 7=9 ; \mathrm{G} 8=9 ; \mathrm{G} 9=7$ and $\mathrm{G} 10=9$ ). All participants were waiting told to act as if they were waiting for the bus.

\section{Level 0}

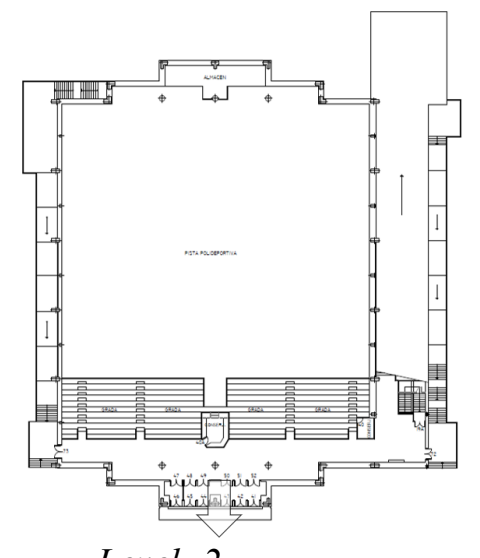

Level -2

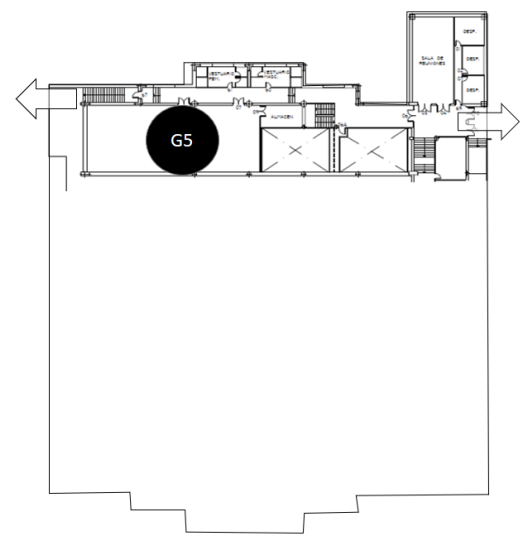

Level -1

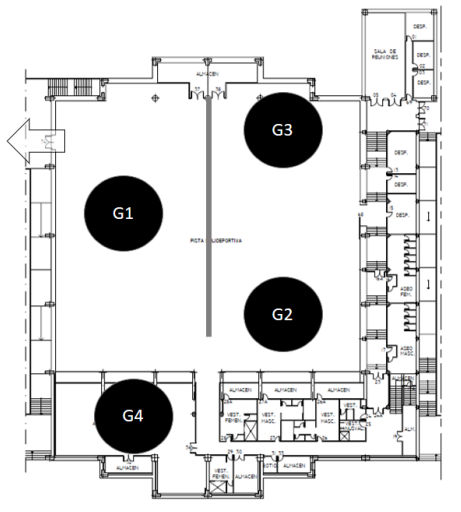

Level -3

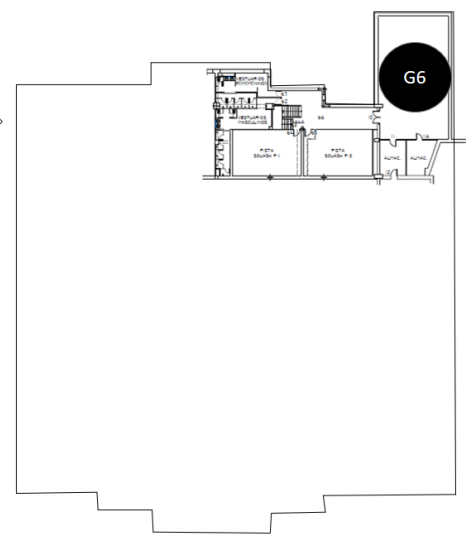

Fig. 2: Initial distribution of occupants in the sports centre before the alarm $(\mathrm{G} 1=11$ occupants playing football; G2=9 occupants playing badminton; G3=11 occupants working out Cross Fit; G4=32 occupants in the gym; G5=6 occupants dancing and G6=9 occupants doing yoga). 
Level 1

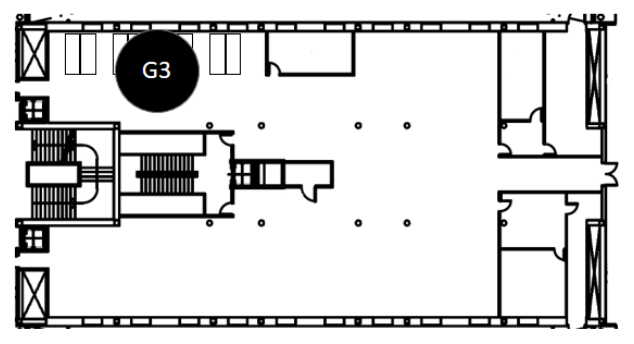

Level 0

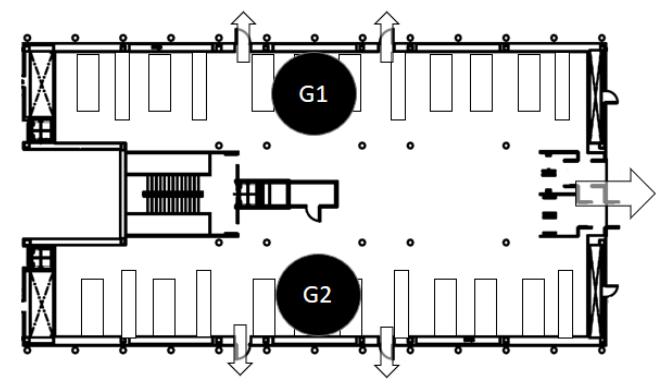

Fig. 3: Initial distribution of occupants in the library before the alarm ( $\mathrm{G} 1=10$; occupants reading; $\mathrm{G} 2=10$ occupants reading; $\mathrm{G} 3=13$ occupants using computers).

\section{Results}

The aim of this section is to determine quantitatively the collective behaviour of evacuees involved in the three different evacuation scenarios. It should be noted that people reached a consensus decision regarding the direction of evacuation in the bus station and the sport centre i.e. people from the same predefined group used the same exit. This is a conditio sine qua non for the application of the proposed method. Fig. 4 shows the maximum, minimum and mean values of the measured variables for each potential group allowing a preliminary visual information of the current analysis.

Bus station
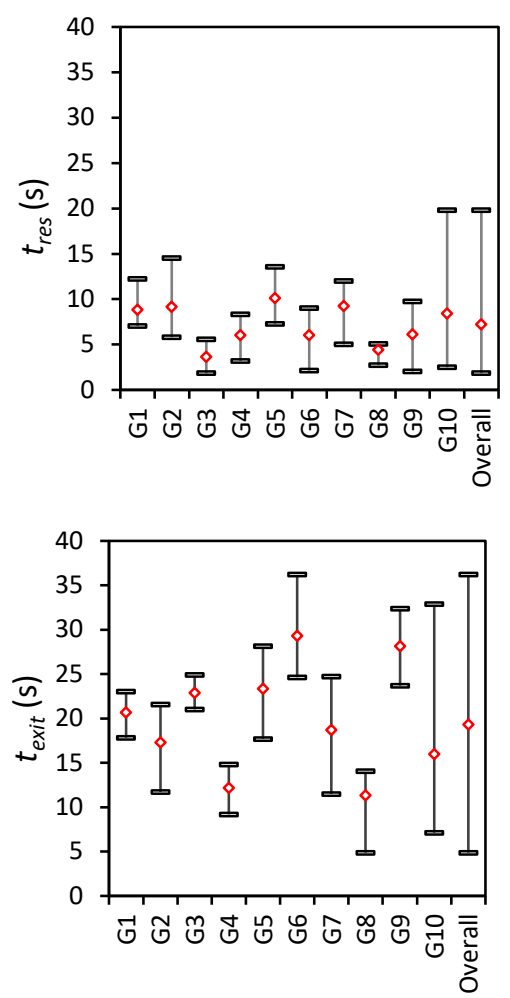

Sports centre
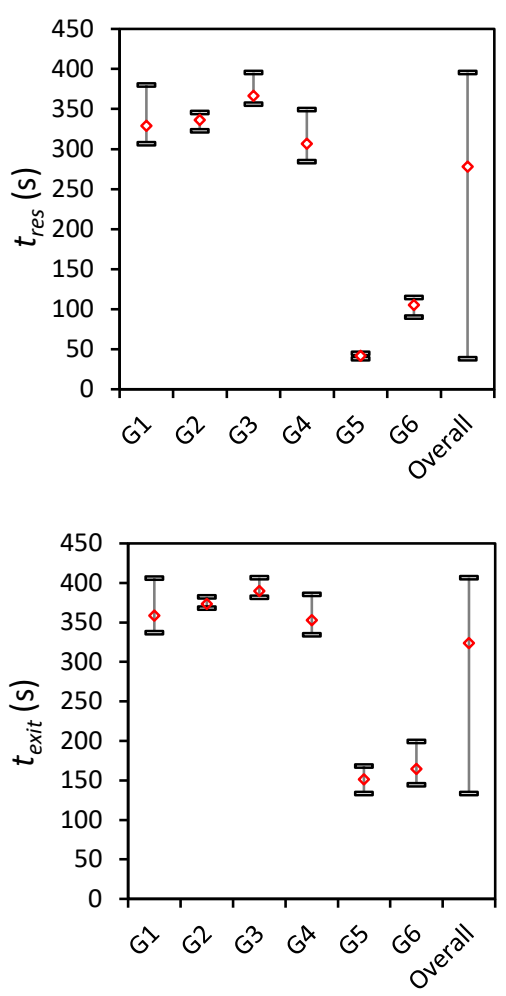

Library
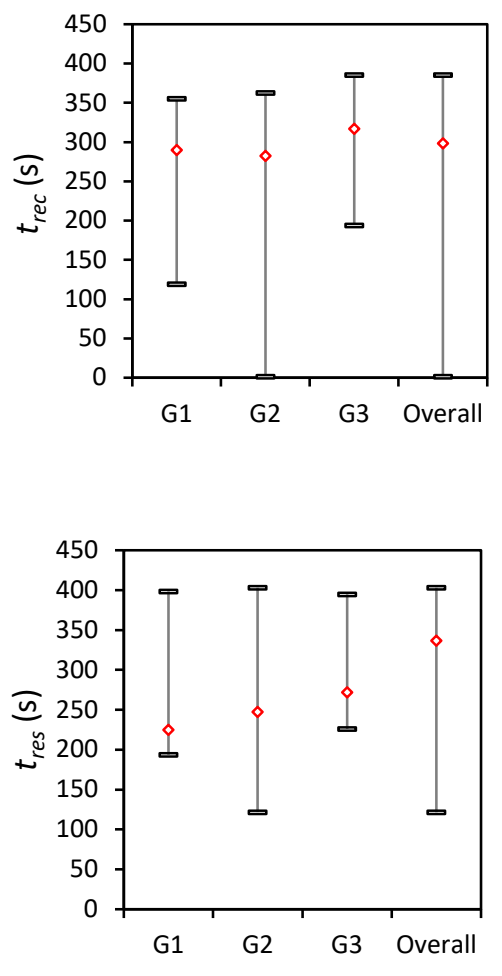

Fig. 4: Range and mean values of the variables measured for each potential group of the three evacuation scenarios. 
The variability relative to the mean of data observed in the bus station differs from potential group to potential group (for $t_{\text {res }} \mathrm{CV}_{\mathrm{G} 1}=0.23 ; \mathrm{CV}_{\mathrm{G} 2}=0.37 ; \mathrm{CV}_{\mathrm{G} 3}=0.45 ; \mathrm{CV}_{\mathrm{G} 4}=0.25 ; \mathrm{CV}_{\mathrm{G} 5}=0.26 ; \mathrm{CV}_{\mathrm{G} 6}=0.41$; $\mathrm{CV}_{\mathrm{G} 7}=0.27 ; \mathrm{CV}_{\mathrm{G} 8}=0.18 ; \mathrm{CV}_{\mathrm{G} 9}=0.40 ; \mathrm{CV}_{\mathrm{G} 10}=0.74$ and for texit $\mathrm{CV}_{\mathrm{G} 1}=0.10 ; \mathrm{CV}_{\mathrm{G} 2}=0.17 ; \quad \mathrm{CV}_{\mathrm{G} 3}=0.06$; $\left.\mathrm{CV}_{\mathrm{G} 4}=0.17 ; \quad \mathrm{CV}_{\mathrm{G} 5}=0.19 ; \quad \mathrm{CV}_{\mathrm{G} 6}=0.15 ; \quad \mathrm{CV}_{\mathrm{G} 7}=0.20 ; \quad \mathrm{CV}_{\mathrm{G} 8}=0.24 ; \quad \mathrm{CV}_{\mathrm{G} 9}=0.10 ; \mathrm{CV}_{\mathrm{G} 10}=0.60\right)$. The data collected reveals in general low variability relative to the mean in the sport centre during the response phase (for $t_{\text {res }} \mathrm{CV}_{\mathrm{G} 1}=0.06 ; \mathrm{CV}_{\mathrm{G} 2}=0.02 ; \mathrm{CV}_{\mathrm{G} 3}=0.03 ; \mathrm{CV}_{\mathrm{G} 4}=0.06 ; \mathrm{CV}_{\mathrm{G} 5}=0.37 ; \mathrm{CV}_{\mathrm{G} 6}=0.08$ ) and the movement phase (for texit $\mathrm{CV}_{\mathrm{G} 1}=0.06 ; \mathrm{CV}_{\mathrm{G} 2}=0.01 ; \mathrm{CV}_{\mathrm{G} 3}=0.02 ; \mathrm{CV}_{\mathrm{G} 4}=0.04 ; \mathrm{CV}_{\mathrm{G} 5}=0.11 ; \mathrm{CV}_{\mathrm{G} 6}=0.09$ ). By contrast, the behaviour of people in the library during the response phase is found to have higher variability in relation to the mean (for $t_{\text {rec }} \mathrm{CV}_{\mathrm{G} 1}=0.31 ; \mathrm{CV}_{\mathrm{G} 2}=0.40 ; \mathrm{CV}_{\mathrm{G} 3}=0.20$ and for $t_{\text {res }} \mathrm{CV}_{\mathrm{G} 1}=0.23 ; \mathrm{CV}_{\mathrm{G} 2}=0.29 ; \mathrm{CV}_{\mathrm{G} 3}=0.16$ ).

Whereas the coefficient of variation $(\mathrm{CV})$ is a measure that provides information of the dispersion of probability distributions, and therefore the behavioural variability among evacuees, it is not sufficient to determine whether participants responded together (as a group) and maintained cohesion with neighbours during the evacuation movement. Hence, the proposed method is applied. In the first step, the statistical test (see section 2.1) was conducted to provide a prima facie evidence of collective behaviour among evacuees. Results of statistical tests are displayed in Table 1. In regard to the bus station, the null hypothesis failed to reject for 3 potential groups (Med Miller $\mathrm{p}=0.35 \pm 0.12$ ) and 4 potential groups (Med C\&P $p=0.43 \pm$ $0.13)$ during the response phase $\left(t_{\text {res }}\right)$. For the movement phase of evacuation $\left(t_{\text {exit }}\right)$ the null hypothesis failed to reject for 7 potential groups (Med Miller and Med C\&P p $=0.66 \pm 0.01$ ). In the sport centre the null hypothesis failed to reject for 5 potential groups (Med Miller and Med C\&P p $=0.90 \pm 0.007$ ) for the response phase $\left(t_{\text {res }}\right)$ whereas all potential groups failed to reject the null hypothesis during the movement phase $\left(t_{\text {exit }}\right)$. The behaviour of evacuees in the library had more variability and the null hypothesis rejected during the response phase $\left(t_{\text {rec }}\right)$ and $\left(t_{\text {res }}\right)$.

Table 1: Statistical tests results $H_{0}: U C V_{i}<L C V_{t}(\alpha=0.05)$.

Cells in F-grey mean a preliminary evidence of collective behaviour.

\begin{tabular}{|c|c|c|c|c|c|c|}
\hline \multirow[t]{2}{*}{ Scenario } & \multirow[t]{2}{*}{$\begin{array}{l}\text { Potential } \\
\text { group }\end{array}$} & \multirow[t]{2}{*}{$\mathbf{N}$} & \multicolumn{2}{|c|}{ Med Miller } & \multicolumn{2}{|c|}{ Med C\&P } \\
\hline & & & $\boldsymbol{t}_{\text {res }}$ & $\boldsymbol{t}_{\text {exit }}$ & $\boldsymbol{t}_{\text {res }}$ & $t_{\text {exit }}$ \\
\hline \multirow{10}{*}{$\begin{array}{l}\text { Bus } \\
\text { station }\end{array}$} & G1 & 6 & $\mathrm{R}$ & $\mathrm{F}$ & $\mathrm{F}$ & $\mathrm{F}$ \\
\hline & G2 & 7 & $\mathrm{R}$ & $F$ & $\mathrm{R}$ & $\mathrm{F}$ \\
\hline & G3 & 6 & $\mathrm{R}$ & $\mathrm{F}$ & $\mathrm{R}$ & $\mathrm{F}$ \\
\hline & G4 & 8 & $\mathrm{~F}$ & $\mathrm{~F}$ & $\mathrm{~F}$ & $\mathrm{~F}$ \\
\hline & G5 & 8 & $\mathrm{R}$ & $\mathrm{R}$ & $\mathrm{R}$ & $\mathrm{R}$ \\
\hline & G6 & 6 & $\mathrm{R}$ & $\mathrm{F}$ & $\mathrm{R}$ & $\mathrm{F}$ \\
\hline & G7 & 9 & $\mathrm{~F}$ & $\mathrm{~F}$ & $\mathrm{~F}$ & $\mathrm{~F}$ \\
\hline & G8 & 9 & $\mathrm{~F}$ & $\mathrm{R}$ & $\mathrm{F}$ & $\mathrm{R}$ \\
\hline & G9 & 7 & $\mathrm{R}$ & $\mathrm{F}$ & $\mathrm{R}$ & $\mathrm{F}$ \\
\hline & G10 & 9 & $\mathrm{R}$ & $\mathrm{R}$ & $\mathrm{R}$ & $\mathrm{R}$ \\
\hline & & & $\boldsymbol{t}_{\text {res }}$ & $t_{\text {exit }}$ & $\boldsymbol{t}_{\text {res }}$ & $t_{\text {exit }}$ \\
\hline \multirow{6}{*}{$\begin{array}{l}\text { Sports } \\
\text { centre }\end{array}$} & G1 & 11 & $\mathrm{~F}$ & $\mathrm{~F}$ & $\mathrm{~F}$ & $\mathrm{~F}$ \\
\hline & G2 & 9 & $\mathrm{~F}$ & $\mathrm{~F}$ & $F$ & $\mathrm{~F}$ \\
\hline & G3 & 11 & $\mathrm{~F}$ & $\mathrm{~F}$ & $\mathrm{~F}$ & $\mathrm{~F}$ \\
\hline & G4 & 32 & $\mathrm{~F}$ & $\mathrm{~F}$ & $F$ & $\mathrm{~F}$ \\
\hline & G5 & 6 & $\mathrm{R}$ & $\mathrm{F}$ & $\mathrm{R}$ & $\mathrm{F}$ \\
\hline & G6 & 9 & $\mathrm{~F}$ & $\mathrm{~F}$ & $\mathrm{~F}$ & $\mathrm{~F}$ \\
\hline & & & $t_{\text {reac }}$ & $\boldsymbol{t}_{\text {res }}$ & $t_{\text {reac }}$ & $t_{r e s}$ \\
\hline \multirow{3}{*}{ Library } & G1 & 10 & $\mathrm{R}$ & $\mathrm{R}$ & $\mathrm{R}$ & $\mathrm{R}$ \\
\hline & G2 & 10 & $\mathrm{R}$ & $\mathrm{R}$ & $\mathrm{R}$ & $\mathrm{R}$ \\
\hline & G3 & 13 & $\mathrm{R}$ & $\mathrm{R}$ & $\mathrm{R}$ & $\mathrm{R}$ \\
\hline
\end{tabular}


The second step of the methodology involves the application of Eq. (2) which allow us to measure the behavioral cohesion of evacuees and therefore confirm whether they behave as a unit or not. Fig. 5 shows the $\gamma_{B_{i}}$ values produced. Note that the null hypothesis of collective behaviour fails to reject for the cases with $\gamma_{B_{i}}$ values $>0.50$ with a region of uncertainty between 0.44 and 0.50 . As explained above, the closer the $\gamma_{B_{i}}$ to 1 the more behavioural cohesion of the group members. Values between 0.50 and 0.75 denote cohesion while values between 0.75 and 1 represent a strong behavioural cohesion among evacuees.
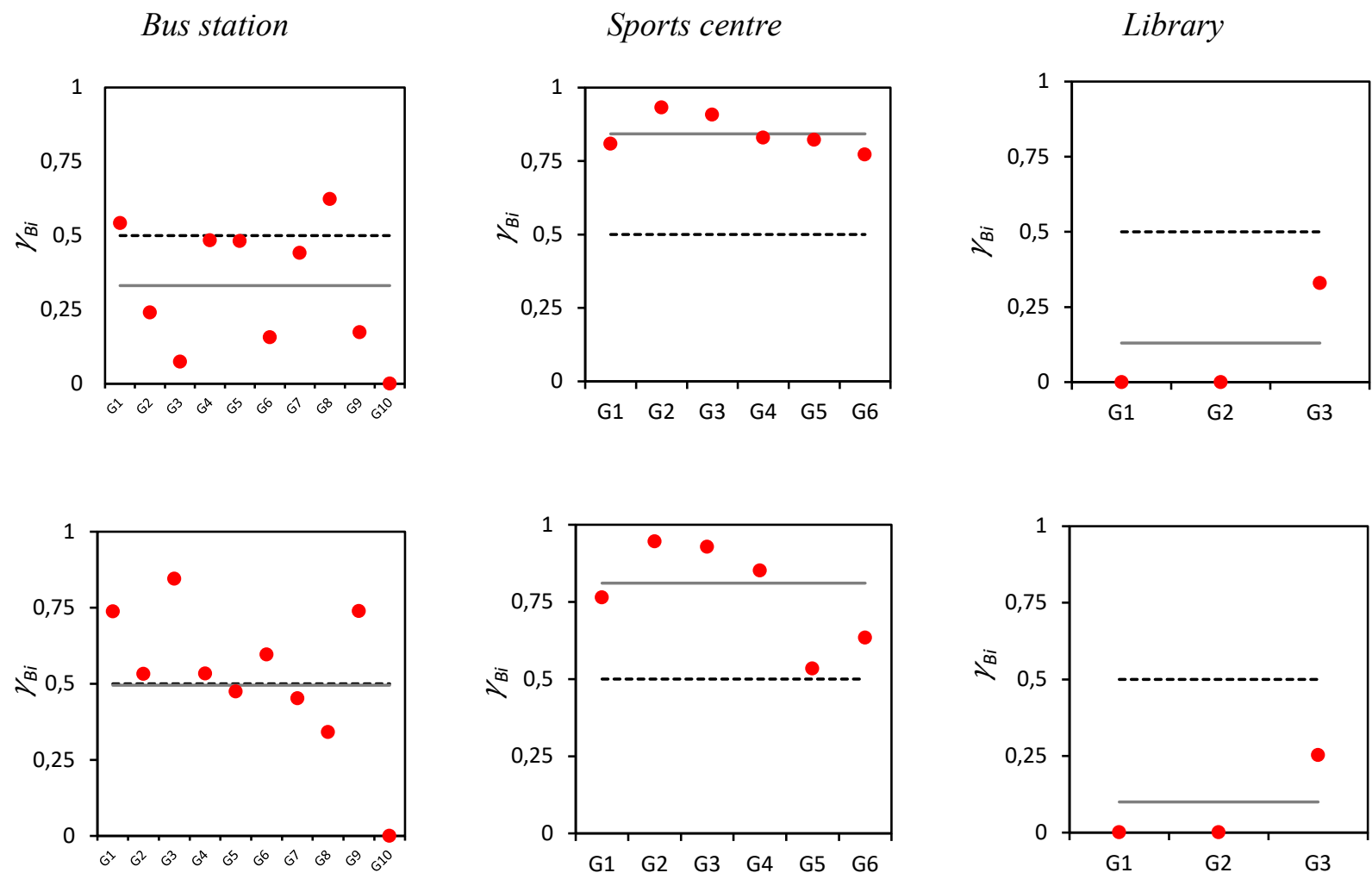

Fig.5. $\gamma_{B_{i}}$ values for $t_{r e s}$ variable during the evacuation. Dashed line is the minimum threshold for group behavioural cohesion $\left(\gamma_{B_{i}}=0.5\right)$ and line in grey is the weighted coefficient to characterize the degree of behavioural cohesion of the evacuation scenario.

In the bus station, the behavioural cohesion during the response phase was found in two groups $(\mathrm{G} 1=0.54 ; \mathrm{G} 8=0.62)$. Other potential groups produced values close to 0.5 (G4=0.48; $\mathrm{G} 5=0.48 ; \mathrm{G} 7=0.44)$. However, these values are considered in a region of uncertainty. The behavioural cohesion during the movement phase of evacuation was confirmed in more groups G1 (0.73), G2 (0.53), G3 (0.84), G4 (0.53), G6 (0.59) and G9 (0.73). Despite some responded individually, evacuees tended to assume the speed of the slowest member or increasing their speed to maintain the cohesion.

In the sport centre, a different process was observed. Results in Fig. 5 confirm that the response of evacuees was very close to each other $(\mathrm{G} 1=0.81 ; \mathrm{G} 2=0.93 ; \mathrm{G} 3=0.91 ; \mathrm{G} 4=0.83 ; \mathrm{G} 5=0.82 ; \mathrm{G} 6=0.77)$. Note that groups G1, G2, G3 and G4 were warned by staff members. Groups G5 and G6 started evacuation by themselves and produced a decrease in the behavioural cohesion (from 0.82 to 0.53 in G5) and (from 0.77 to 63 in G6) due to the long distances the occupants had to cover to leave the building, but they still kept united. 
Based on results in Fig. 5, no behavioural cohesion in evacuees was found in the library. Despite some students were in small groups before the alarm (two or three friends), they behaved independently during the response phase of evacuation. Some started evacuation activities and some others ignored the alarm, and continued reading or using computers, as they did not recognize the alarm relevant to their situation. It should be noted that these occupants needed the staff intervention to physically undertake evacuation activities. Furthermore, all people in the library performed different tasks before starting the purposive evacuation movement such as shutting down laptops, packing work items, packing/collecting personal belongings, putting on jackets, moving to another location to perform an action. The time spent on these tasks varied considerably (G1 mean $46.81 \mathrm{~s}$ and standard deviation $19.37 \mathrm{~s}$; G2 mean $47.61 \mathrm{~s}$ and standard deviation $32.80 \mathrm{~s}$; G3 mean 25.12 and standard deviation $19.77 \mathrm{~s}$ ) thus increasing the variability in the response phase of evacuation.

\section{Discussion}

Groups are likely to emerge during evacuation. However very little is still known about how and why this happens. For example, we do not know what the actual influence of collective behaviour on decision making and actions performed by people during evacuation process is. Based on the fact that consensus and uniformity denote a reduction in the behavioural variability, we have proposed a possible approach to identify evacuation groups and measure the behavioural cohesion of group members. The presented method is expected to improve our understanding of the conditions in which such behaviours take place.

An illustrative case study has been presented through the analysis of three evacuation scenarios: a bus station, a sports centre and a library involving 185 evacuees divided in 19 potential evacuation groups. We confirmed the presence of collective behaviour in the bus station and the sport centre in $60 \%$ and $100 \%$ of potential evacuation groups respectively. Contrary to expectations, no evidence of collective behaviour was found in the library. Despite having visual and verbal contact, occupants responded individually and performed different tasks before start evacuation (collecting belongings, shutting down lab tops, etc.) thus increasing the behavioural variability. This suggests that proximity could be important but not always a key factor in collective evacuation behaviour. Social ties, whether occupants share activities before the evacuation and/or the type of alarm could be also important factors to consider. This is an example of the importance of using the proposed method. For instance, implementing the same pre-evacuation time distribution to all occupants could be a good approach for the evacuation analysis of a library but potentially unrealistic in other evacuation scenarios where some groups are likely to emerge during evacuation.

The main contribution of this paper is suggesting the use of Eq. (2) as a fast and simple approach to conduct a preliminary assessment of collective behaviour for any evacuation scenario. If $\gamma_{B_{i}}>0.50$ the collective behaviour can be confirmed and the higher the $\gamma_{B_{i}}$ value the higher the behavioural cohesion in evacuees. Values from 0.50 to 0.75 denote a high cohesion while values $>0.75$ represent a very strong behavioural cohesion in evacuees. It is worth to remind that an ideal value of 1 would represent a perfect synchronization on people actions.

Care is required however when using the proposed method as it has a number of limitations. The first limitation is that the identification of the potential groups for the analysis relies on the analyst. A plausible approach could be, for instance, the specific location (room, zone, area, queue, etc.), the proximity where occupants are likely to interact (verbal and/or non-verbal communication) and/or whether they share a target before the alarm. The second limitation is that the members of the potential group should use the same exit, when analysing the movement phase of evacuation. The third limitation is that the number of members in the potential evacuation group should be higher enough to calculate the coefficients of variation (i.e. more than 5). The fourth limitation is that the results are very sensitive to divergent behaviours of individuals (extreme values). For instance, given a defined group, it only takes an individual who acts separately to discard behavioural cohesion although the rest of group members behave as a group. This limitation may be solved through the application and inclusion of outliers detection methods. Nevertheless, this is very complicated for small sample sizes $(\mathrm{N}=[5-25])$. 


\section{Acknowledgements}

The authors would like to thank the European Union for the LETS-CROWD project received funding from the Horizon 2020 Research and Innovation Programme under the grant agreement $\mathrm{N}^{\circ}$ 740466 and the Spanish Ministry of Economy and Competitiveness for DEFENDER Project Grant, Ref: BIA2015-64866-R, co-funded by ERDS funds.

\section{References}

[1] B. Latane, and J.M. Darley, "Group inhibition of bystander intervention emergencies", Journal of Personality and Social Psychology, vol. 10, pp. 215-221, 1968.

[2] R. H. Turner and L. M. Killian. Collective Behaviour. Englewood Cliffs, NJ: Prentice Hall, Inc., 1987.

[3] B. E. Aguirre, D. Wenger and G. Vigo, "A test of the emergent norm theory of collective behaviour", Sociological Forum, vol. 13, no. 2, pp. 301-320, 1998.

[4] E. L. Quarantelli, "The Nature and Conditions of Panic", American Journal of Sociology, vol. 60, no. 3, pp. 267-275, 1954.

[5] E. Kuligowski, "Human Behaviour in Fire", in SFPE Handbook of Fire Protection Engineering, 2016, pp. 2070-2114.

[6] A. Cuesta, O. Abreu and D. Alvear, "Methods for measuring collective behaviour in evacuees", Safety Science, vol. 88, pp. 54-63, 2016.

[7] W. Panichkitkosolkul, "Asymptotic confidence interval for the coefficient of variation of Poisson distribution: a simulation study”, Maejo International Journal of Science and Technology, vol. 4, pp. $1-7,2010$.

[8] M. Gulhar et al., "A comparison of some confidence intervals for estimating the population coefficient of variation: a simulation study", Statistics and Operations Research Transactions, vol. 36, no. 1, pp. 45-68, 2012.

[9] G. E. Miller, "Asymptotic test statistics for coefficients of variation", Communications in StatisticsTheory Methods, vol. 20, no. 10, pp. 3351-3363, 1991.

[10] G. E. Miller and Karson, "Testing the equality of two coefficients of variation", American Statistics. Association: Proceedings of the Business and Economic Section, Part I, pp. 278-283, 1977.

[11] J. D. Curto and J. C. Pinto, "The coefficient of variation asymptotic distribution in the case of non-iid random variables", Journal of Applied Statistics, vol. 36, no. 1, pp. 21-32, 2009. 